\title{
El paisaje en la interpretación del patrimonio industrial. Los puertos
}

\section{The landscape on industrial heritage interpretation. The ports}

\author{
YANELI LEAL DEL OJO DE LA CRUZ
}

Yaneli Leal del Ojo de la Cruz, "El paisaje en la interpretación del patrimonio industrial. Los puertos", ZARCH 16 (junio 2021):78-89. ISSN versión impresa: 2341-0531 / ISSN versión digital: 2387-0346.

https://doi.org/10.26754/ojs_zarch/zarch.2021165690

Recibido: 10-12-2020 / Aceptado: 16-03-2021

\section{Resumen}

En la segunda mitad del siglo xx, con el cambio de los ideales artísticos y la apertura de las políticas patrimoniales, se incluyó la industria como patrimonio cultural. No obstante, todavía encuentra cierta resistencia y poca visibilidad, lo que conlleva la pérdida, degradación y mal manejo de muchos bienes y sitios industriales con valor patrimonial. En este artículo se analizan los factores que han provocado conflicto en su interpretación, y encuentra en el análisis integral del paisaje cultural la clave para la justa valoración del patrimonio industrial. Utiliza el paisaje portuario como ejemplo de la interdependencia entre industria y paisaje, lo que permite identificar mejor su impacto a nivel territorial, social, económico, político y cultural. En síntesis, fundamenta la necesidad de establecer como base de la gestión eficiente, una metodología basada en los estudios del paisaje y como tal, caracterizada por la interdisciplinariedad, abierta, flexible y con varios niveles de interpretación del patrimonio, y su integración en la comunicación y educación patrimonial de la sociedad contemporánea.

\section{Palabras clave \\ Patrimonio industrial, paisaje cultural, gestión, puertos}

\begin{abstract}
In the second half of the 20th century, with the change in artistic ideals and the opening of patrimonial policies, industry was included in cultural heritage. However, industrial heritage still comes across some resistance and little visibility, which leads to the loss, degradation and mismanagement of many valuable assets and industrial sites. This article analyzes the conflictive factors on its interpretation, and finds in the comprehensive analysis of the cultural landscape the key to the fair valuation of industrial heritage. It presents the port landscape as an example of the interdependence between industry and landscape, which allows better to know its impact at the territorial, social, economic, political and cultural level. In summary, it explains the need to establish an open and flexible methodology based on landscape studies for efficient management, which should be characterized by interdisciplinarity to pursue various levels of heritage interpretation, and must be expand to communication and heritage education of contemporary society.
\end{abstract}

\section{Keywords}

Industrial heritage, cultural landscape, management, ports

Yaneli Leal del Ojo de la Cruz nació en La Habana en 1985, es Licenciada en Historia del Arte por la Universidad de La Habana (2011), y Máster en Ciencias para la conservación del patrimonio edificado, por la Universidad Politécnica de La Habana José Antonio Echeverría, CUJAE (2015). Actualmente, cursa el segundo año del Doctorado en Patrimonio Arquitectónico, de la Facultad de Arquitectura de la Universidad Politécnica de Madrid. Profesora universitaria e investigadora especializada en patrimonio construido, entre 2011 y 2019 impartió las asignaturas de Historia del Arte e Historia de la Arquitectura en la carrera de Preservación y Gestión del Patrimonio Cultural, del Colegio Universitario San Gerónimo de La Habana. Ha publicado los libros: Los Jardines de La Tropical (La Habana: Ediciones Boloña, 2014) y El patrimonio urbano del sur de La Habana (New York: Peter Lang Publishing, 2020). 
Uno de los grandes desafíos en la salvaguarda del patrimonio ha sido considerar qué se preserva y qué no, lo que conlleva una postura de altísima responsabilidad cultural y moral respecto a la memoria histórica, a las generaciones futuras y al derecho que tenemos al patrimonio compartido. Ese reto se amplifica cuando se debe decidir cómo preservar el bien y cuál sería el diseño de gestión sociocultural que necesariamente debe acompañarle y mantenerse luego. La situación se torna más compleja cuando la valoración del monumento o sitio patrimonial está matizada por elementos de controversia, ya sea por su relación con personalidades o sucesos negativos; por sus niveles de integridad y autenticidad; y/o porque ya no resulte compatible con los conceptos estéticos, medioambientales y de desarrollo de la sociedad contemporánea.

El patrimonio industrial suele verse asociado a estas condicionantes, por lo que enfrenta importantes dificultades para su salvaguarda, a pesar del reconocimiento que tiene en las instituciones especializadas en patrimonio, y en las leyes y documentos normativos que a su favor se han redactado. Es frecuente la pérdida de muchas estructuras y conjuntos valiosos, ya sea por su condición ruinosa o porque el desconocimiento y la indolencia han llevado a su demolición o transformación radical. Ello demuestra que aún no se ha hecho suficiente en la divulgación de los valores del patrimonio industrial; en la concienciación de su importancia en distintos ámbitos culturales, donde incluso ha tenido un papel activo en la conformación de la identidad local; en su relación con el entorno urbano inmediato; en su condición de símbolo, referente o simple hito; y en su capacidad natural para el cambio, para servir como elemento dinámico de la economía, incluso desde su vínculo con la cultura local más allá de las funciones industriales.

Entre las distintas áreas de la industria, los puertos constituyen un ejemplo de excepcional riqueza por su carácter, por su relación con otras industrias - muchas veces incluidas directamente en su territorio y dinámica funcional-, y por la influencia económica y cultural que ejercen sobre el espacio urbanizado que de ellos deriva, cuya identidad han ido moldeando durante siglos.

En este artículo se pretende analizar lo que se ha definido sobre este tema, para entender los conflictos que la industria afronta desde su identificación y valoración como objeto patrimonial; para ello reflexiona sobre los puntos débiles de la interpretación del patrimonio industrial y sobre la perspectiva paisajística como una solución necesaria. Asimismo, se expone la necesidad de extender esa apreciación a toda la sociedad a través de la educación patrimonial. De este modo, al mismo tiempo que aporta una síntesis de lo teorizado, se proponen cambios en el marco temporal establecido por los documentos rectores, se alerta sobre la ambigüedad del concepto de patrimonio industrial en relación con lo tecnológico, y se amplían los valores que pueden ser identificados en los bienes industriales. El puerto, entendido como un paisaje industrial por excelencia, constituye un buen ejemplo para la concreción de algunas premisas, aplicables a otros siempre que se respeten sus particularidades.

\section{Caracterización y evolución del patrimonio industrial portuario}

Con una amplia presencia a nivel mundial —en cantidad y variedad - , el patrimonio industrial ha constituido parte sustancial de la vida de los pueblos, transitando por diferentes etapas que han marcado no solo el desarrollo económico, sino también la evolución de la sociedad y la cultura misma. Su afiliación a los cambios tecnológicos, al uso de nuevos materiales, sistemas de producción y comunicación, ha repercutido notablemente en todas las esferas de la vida y dinámicas sociales; por lo cual su análisis patrimonial debe ir más allá de la valoración de las estructuras y procesos industriales en sí mismos. 


\section{ZARCH No. 16 | 2021}

Rehaciendo el patrimonio arquitectónico controvertido, repensando el espacio público

Remaking Contested Architectural Heritage, Rethinking Public Space

\section{YANELI LEAL DEL OJO DE LA CRUZ}

El paisaje en la interpretación del patrimonio industrial. Los puertos

The landscape on industrial heritage interpretation. The ports
En su evolución natural y también en su apreciación, la industria ha vivido diferentes etapas. Como antecedente se entienden las industrias tradicionales anteriores al siglo XVIII, clasificadas como protoindustria. El gran salto está marcado por la Revolución Industrial; sin embargo, la protoindustria ha sido reconocida por la fácil identificación de sus valores de antigüedad, artístico y arquitectónico. Incorporarla al marco temporal que definen los documentos normativos para el patrimonio industrial, permitiría un estudio más coherente del mismo. Esto resulta imprescindible para el análisis de algunos paisajes industriales como el de los puertos, los cuales asientan su significado con anterioridad al siglo XVIII:

\footnotetext{
"Por la propia dinámica económica del puerto, se convertirá ya en la protohistoria, en un lugar de localización industrial preferente.

Astilleros, talleres de cordelería, talleres para tejer y armar velas, carpinterías, tabernas y centros de hospedaje, almacenes y casas de cambio configuran un espacio preindustrial de gran importancia para los países que disponían de esas instalaciones. Allí encontraremos gran parte de los avances técnicos, invenciones e innovaciones, que han condicionado la vida económica de las sociedades hasta bien entrada la Edad Contemporánea".2
}

Junto a esto, otros conflictos en la identificación del patrimonio industrial están marcados por la fuerte relación que tiene con lo tecnológico, difuminando los límites entre industria e ingeniería, cuya apreciación queda sustentada por disímiles pero legítimos puntos de vista. Tiene además la industria una importante conexión con los procesos de producción, distribución y comercio de bienes, por lo que en su análisis es imprescindible el estudio del sistema que conforma. Dado el caso, el enfoque interdisciplinar desde la perspectiva del paisaje resulta la alternativa más esclarecedora.

Como espacio funcional, los puertos han pasado por diferentes etapas en las que han tenido que readecuarse a los requerimientos técnicos de las embarcaciones. El desarrollo tecnológico ha sido siempre su principal motivo de transformación. Antiguamente, también se sumaron los afanes de su fortificación y defensa, para lo cual contaron con la ejecutoria de ingenieros militares y arquitectos de prestigio, a quienes también corresponden muchos inmuebles y espacios públicos del entorno portuario.

Los requerimientos de los buques que han determinado el emplazamiento de los puertos y su configuración espacial son: los sistemas de propulsión, las facilidades de maniobra, el calado y las exigencias para la carga y descarga de mercancías. Inicialmente, la infraestructura portuaria no era muy compleja. Incluso los puertos españoles que llegaron a establecer una importante red de comunicación marítima entre Europa y América, tuvieron en su mayoría instalaciones y estructuras muy precarias hasta el siglo XIx. Diques, escolleras u obras de abrigo, muelles, arsenales y astilleros, y fortalezas destacan entre las primeras obras realizadas en ellos.

Entre los siglos XVI y XVIII, las dimensiones de las embarcaciones no fueron muy contrastantes. ${ }^{3}$ El gran cambio llegó con la máquina de vapor y el uso del hierro en el siglo XIX. Entonces el barco de vapor superaba los 100m de largo, y ofrecía mayor velocidad y seguridad en las distancias a recorrer. Como consecuencia de la mayor capacidad de carga del navío y de la mayor demanda de las modernas industrias condicionada por la mecanización de los procesos productivos, se requirieron almacenes más grandes, sistemas más sofisticados para la carga y descarga de mercancías y muelles de gran longitud, calado y amplitud. Esto exigió dragar o alejarse de la costa con cimentaciones de mayor profundidad. Las instalaciones industriales del puerto alcanzaron más significación y diversificación, al consolidarse como punto estratégico de producción e intercambio. Su relación con el hinterland se vio también ampliada al conectarse de manera expedita a través del ferrocarril, el cual favoreció el desplazamiento inmediato de las mercancías, 
Figura 1. Red ferroviaria que atraviesa parte de la zona industrial de la bahía de La Habana. Fotografía de Alejandro Leal del Ojo.

Figura 2. Vista inferior de los elevados construidos en la Avenida del Puerto. Fotografía de Alejandro Leal del Ojo.
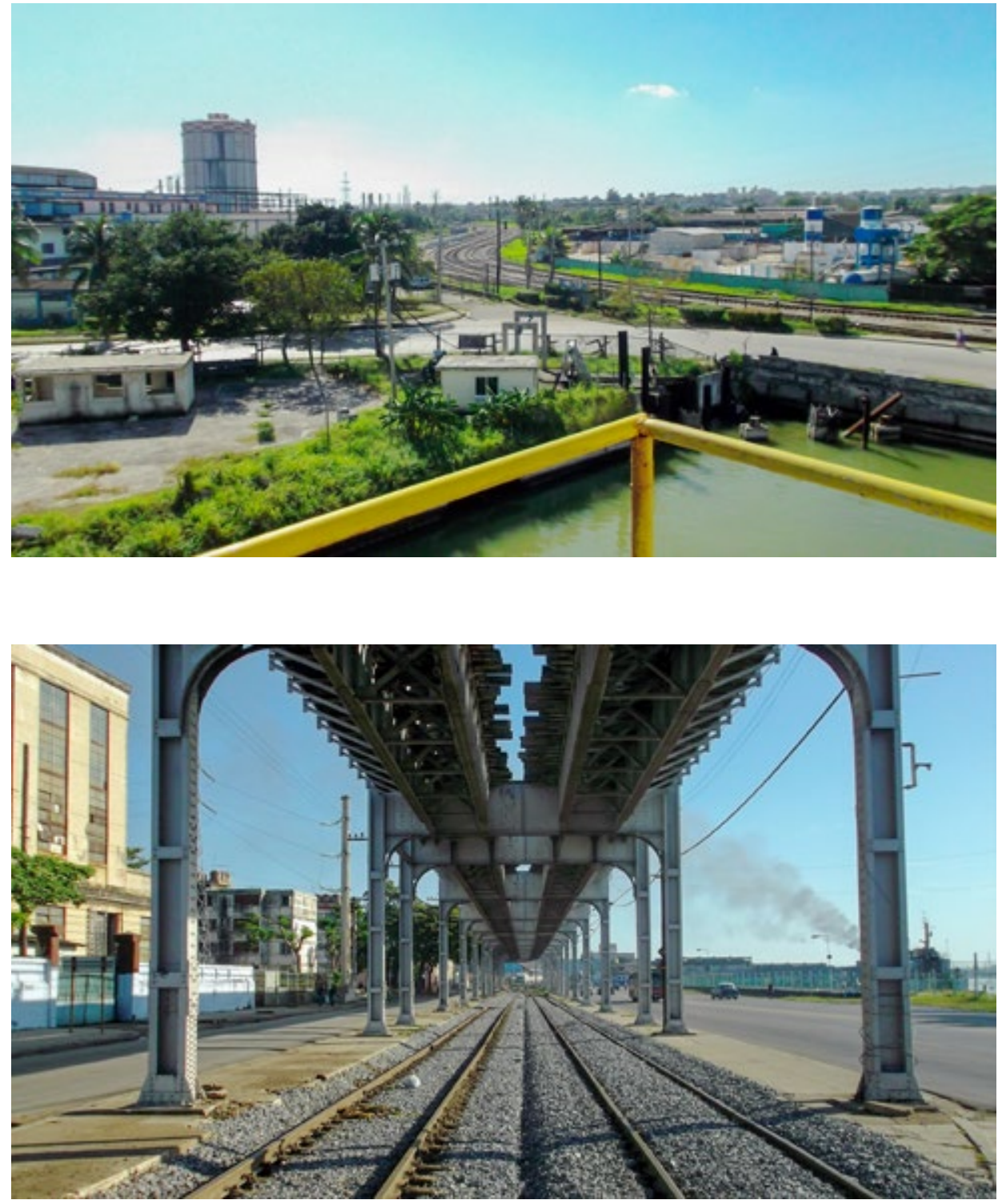

su consumo y comercio hacia un extenso territorio. Paralelamente, la ciudad se separó del puerto en la medida en que este se afiliaba más a la industria, lo cual resultaba una paradoja, pues esta última definía parte importante del desarrollo y la vida urbana.

La consecuente reestructuración del espacio portuario se solucionó de diversas maneras: con un mejor aprovechamiento del uso del suelo, con el avance de los muelles hacia el mar o con el traslado de las funciones portuarias hacia otros espacios menos centrales y con mayor disponibilidad de terreno. En algunos casos, estas labores corresponden con la demolición de las murallas de mar que defendían el puerto y la ciudad, y que para entonces se consideraban obsoletas.

Asimismo, la instalación del entramado de líneas férreas y estaciones del ferrocarril vinculadas al puerto, en algunos casos obligaron al rediseño del borde marítimo, desplazando muelles y almacenes hacia el mar, y ganando espacio para la construcción incluso de nuevos inmuebles residenciales e industriales. Desde el punto de vista urbano, la instalación de las vías del ferrocarril en torno al puerto ha sido considerada una fractura física y visual que coadyuvó a la paulatina separación del puerto y la ciudad, acentuada por la fuerte industrialización que tuvo lugar a partir del siglo XIX.

Sobre mediados del XX, los puertos volvieron a vivir otro significativo cambio producido por la obsolescencia de las estructuras del siglo anterior. Una vez más 
ZARCH No. 16 | 2021

Rehaciendo el patrimonio arquitectónico controvertido, repensando el espacio público

Remaking Contested Architectural Heritage, Rethinking Public Space

\section{YANELI LEAL DEL OJO DE LA CRUZ}

El paisaje en la interpretación del patrimonio industrial. Los puertos

The landscape on industrial heritage interpretation. The ports
4 Actualmente, los buques de contenedores pueden alcanzar los 400m de eslora, y algunos cruceros sobrepasan los 300m. En cuanto a su capacidad, los buques y las estructuras portuarias destinadas a la carga y descarga, han vivido un proceso evolutivo muy dinámico. Téngase en cuenta que en 1968 los portacontenedores tenían una capacidad de 750TEU (Twenty-foot Equivalent Unit), en 1998 de 7.900TEU y en 2011 alcanzaban los 18.000TEU.

5 Centro de Estudios Paisaje y Territorio, El Paisaje en la Ordenación y Gestión de los Puertos de Andalucía (Sevilla: Agencia Pública de Puertos de Andalucía y Consejería de Fomento y Vivienda de la Junta de Andalucía, 2015), 54.

6 Miguel Ángel Aníbarro y Esther Valdés, "Fascinante y detestable. Artelización e integración de los paisajes industriales", Cuaderno de Notas. Publicación sobre temas de teoría e historia de la arquitectura (julio 2016): 1.

7 Zandor Gomes, "O patrimônio industrial como elemento da paisagem cultural e a paisagem cultural conformando o patrimônio industrial: uma relação conceitual", Espaço e Cultura (julio-diciembre 2016): 36-7. el avance tecnológico dictó y homogeneizó las pautas a seguir, vinculadas a las nuevas formas de depósito de mercancías con el uso de contenedores. ${ }^{4}$ El puerto era una pieza más de la cadena de producción y los requerimientos del sistema trasladaron las terminales de contenedores hacia zonas con acceso a otros medios de transporte. Como consecuencia aparecieron los puertos secos, terminales interiores sin relación con el agua donde se almacenan los contenedores que parten a través del ferrocarril, de aeropuertos de carga o red de carreteras hacia todos los puntos de distribución. ${ }^{5}$

En resumen, en el siglo xx, el espacio urbanizado se multiplicó y se alejó del puerto, definiendo nuevas zonas de centralidad. Paralelamente, la ciudad invirtió en otras esferas de la economía y la industria, por lo que el carácter portuario perdió protagonismo y pasó a coexistir con otras áreas de desarrollo económico. A este período también corresponde el auge de la aviación, el deterioro de los centros históricos y la desindustrialización de algunos barrios, por lo que el entorno portuario comenzó a ser visto como un espacio marginal y decadente. Eso también implicó el movimiento de poblaciones, cambios en la estructura socioprofesional, y la consecuente pérdida de tradiciones.

\section{La valoración patrimonial de la industria}

Para evitar errores de procedimiento que pudieran resultar irreversibles, muy especialmente en aquellos bienes que plantean un conflicto por su carácter, historia y condición, debe abogarse por un análisis valorativo interdisciplinar que visibilice la variedad de fundamentos que lo envuelven. Una postura conciliadora que aporte abundante información resulta estratégica en la concreción de planes de manejo y gestión, y en la identificación de los actores a involucrar. Además, el análisis holístico contribuye a identificar otros bienes patrimoniales afines aún no visibilizados o valorados correctamente por su situación polémica.

Ha tardado en gestarse una nueva sensibilidad hacia el patrimonio industrial, con desigual reconocimiento y aceptación en diferentes países. Muchas razones conducen a ello, algunas de las cuales van enlazadas a la propia evolución del concepto de patrimonio y a lo que consecuentemente se le ha otorgado valor cultural, protección y difusión. El patrimonio industrial está asociado a la tecnología y a la clase trabajadora. Le caracteriza su aspecto pragmático, funcional, desligado de los grandes temas que hasta hace algún tiempo constituían objeto de estudio de la Academia, reforzado además por su peculiar cualificación estética de austeridad de formas y ornamentos.

Además, muchas de las estructuras industriales se encuentran en desuso y/o representan el recuerdo tangible del impacto medioambiental que el mal manejo de la industria ha generado, por lo que ofrecen una imagen negativa para la sociedad posindustrial. Sobre este sentimiento que refuerza el carácter controversial de la industria, se debaten distintas posturas. Con frecuencia se admite que aceptar su necesidad económica pero rechazar su presencia en el espacio habitado es una actitud hipócrita. ${ }^{6}$ En el caso del puerto, se ha entendido como un elemento independiente de la ciudad, lo cual justifica el predominio de los estudios económicos sobre los culturales.

Los efectos de la industrialización también han llevado a reflexionar sobre la relación del hombre con el medio ambiente: visto que las consecuencias negativas, como la contaminación, inciden en todo el planeta, se constata que nunca más el hombre y el medio ambiente podrán ser analizados de manera independiente. ${ }^{7}$ Varios estudios han verificado la baja tolerancia que la sociedad tiene respecto al impacto de la industria sobre el espacio urbanizado, pero también han ofrecido 


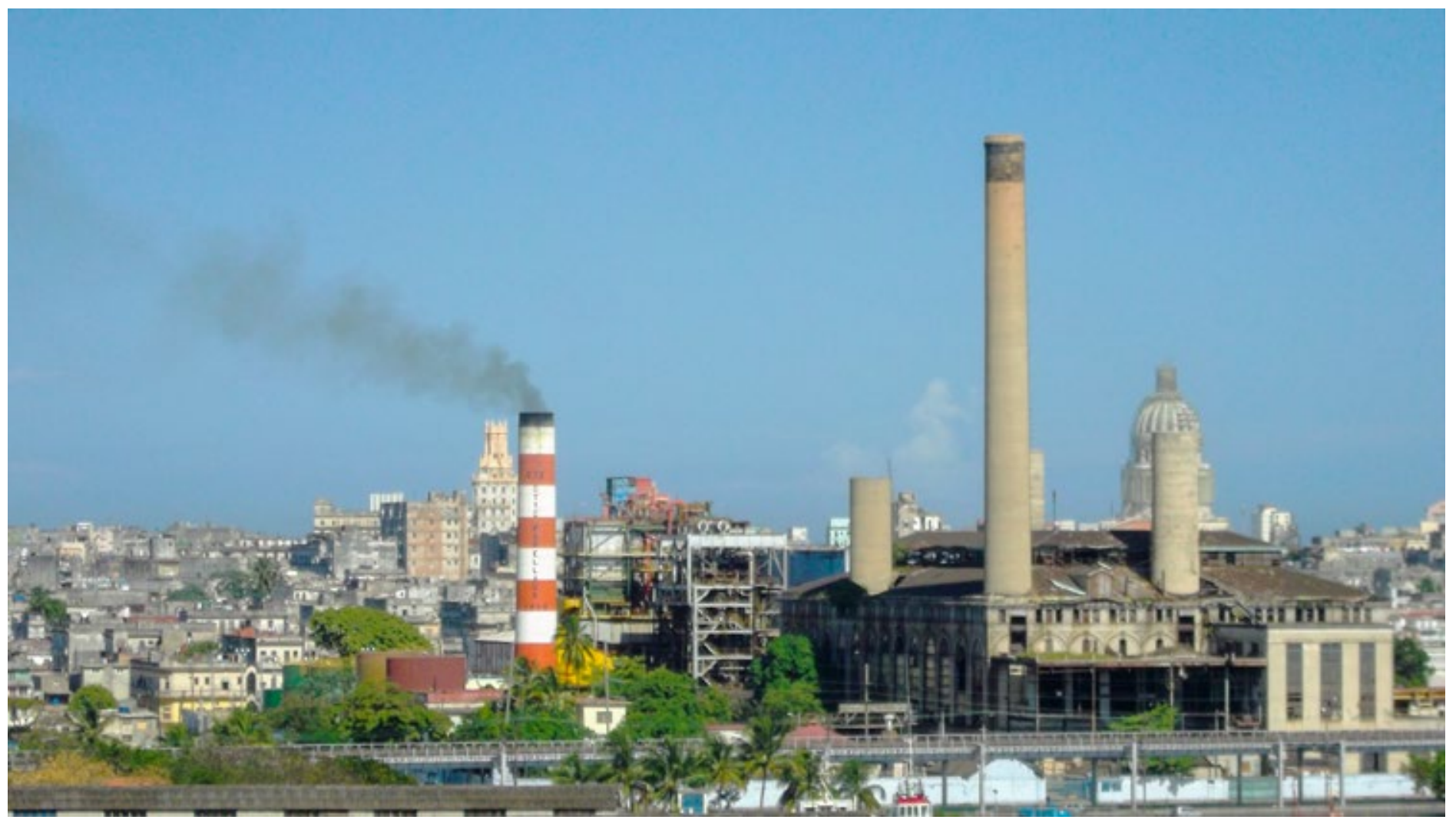

Figura 3. Ruinas de la termoeléctrica Tallapiedra, hito del patrimonio industrial cubano construido junto a la bahía habanera. Fotografía de Alejandro Leal del Ojo

8 Al paisaje portuario se aplica por excelencia la teoría de fijación y flujos de Gene Desfor y Jennefer Laidley. Para estos autores, las fijaciones incluyen los entornos construidos, las estructuras institucionales y reguladoras, y las costumbres culturales; los flujos están dados por los procesos de acumulación de capital, de información, por el empleo, la energía y el conocimiento, entre otros. Aunque se reconoce que contienen significados más complejos y contradictorios. En: Gene Desfor y Jennefer Laidley, "Changing urban waterfronts: a fixity and flow perspective", Portus (n. 21, 2011): 8.

$9 \mathrm{TICCIH}$, "Carta de Nizhny Tagil sobre el Patrimonio Industrial", Moscú, julio de 2003, https://www.icomos.org/18thapril/2006/ nizhny-tagil-charter-sp.pdf (consultada el 13 de junio de 2020): 2 .

10 Sobre ellos aclara Ángela Rojas: “La 'rareza' está más vinculada a la idea de algo que está en vías de desaparición, mientras que la 'unicidad', que guarda una estrecha relación con el valor estético clásico, es lo contrario de lo 'característico' o 'típico', o sea: especificidad, particularidad $y$, a veces, hasta el carácter poco accidental". En: Isabel Rigol y Ángela Rojas, Conservación patrimonial: teoría y crítica (La Habana: Editorial UH, 2012), 378. una adecuada valoración de la dimensión e influencia que en otros sentidos -también positivos-, ha tenido la Revolución Industrial.

Esto llevaría a replantear la gestión de los puertos históricos como espacios de oportunidad para el desarrollo local sostenible, desde la renovación y consolidación de sus vínculos con la ciudad. Para mantener la esencia de la ciudad portuaria y no convertirla en una ciudad costera, deben planificarse en combinación el desarrollo urbano y el portuario, aprovechando la pervivencia de las funciones tradicionales adaptativas, el tratamiento estratégico de los fixities y flows, ${ }^{8}$ y reconociendo que la relación puerto-ciudad es cambiante por naturaleza pero que existe un valor agregado en los lazos culturales que perviven.

Por su significado para el hombre, la interpretación de la industria ha definido tres momentos diferentes: primero fue apreciada por su valor de uso, como símbolo de desarrollo y en realce a su funcionalidad; luego pasó a ser valorada por su condición estética, particularmente vinculada a la imagen de la ruina o de la belleza de la máquina y los materiales industriales, y a la par rechazada como símbolo de contaminación; para finalmente ser defendida por su valor cultural, entendida como patrimonio y recurso para el desarrollo sostenible. La primera etapa corresponde a los primeros 200 años de avance de la sociedad industrial; la segunda se inscribe muy especialmente entre las décadas de 1960 y 1980; y la última tiene lugar a partir de la década de 1980 hasta la actualidad, en lo que ha recibido el nombre de era postindustrial o de la información, por los cambios dados con la digitalización informática.

A los valores del patrimonio industrial se refiere la Carta de Nizhny Tagil, al reconocerle valor histórico, social, tecnológico o científico, estético o arquitectónico, y de rareza. ${ }^{9}$ Todos ellos permiten evaluar parcialmente el bien industrial, pero como monumento aislado. Respecto a la rareza, debe señalarse su condición diferente del valor de unicidad o excepcionalidad, ${ }^{10}$ que también pudiera ser conferido al patrimonio industrial.

Estos valores son los que reconoce el Plan Nacional de Patrimonio Industrial de España, a los que suma: el territorial, el testimonial, de singularidad y/o represen- 


\section{ZARCH No. 16 | 2021}

Rehaciendo el patrimonio arquitectónico controvertido, repensando el espacio público

Remaking Contested Architectural Heritage, Rethinking Public Space

\section{YANELI LEAL DEL OJO DE LA CRUZ}

El paisaje en la interpretación del patrimonio industrial. Los puertos

The landscape on industrial heritage interpretation. The ports
11 Para entender la diferencia entre el valor de documento y el de testimonio, resulta excelente la definición que este autor ofrece de ambos: "El valor de testimonio. Los bienes de la industrialización tienen un valor etnológico o antropológico, porque son testimonio de una época en que fue el protagonista de una gran revolución social y económica que cambió la sociedad y [cuyo] conocimiento es necesario para comprender la sociedad postindustrial actual.

El valor de documento. Los bienes industriales tienen un valor arqueológico en el sentido que son objeto de estudio utilizados para comprender la sociedad industrial y cuyo resultado nos aporta unas informaciones cualitativas de base científica que no se pueden obtener a través de los escritos". En: Eusebi Casanelles, "Nuevo concepto de Patrimonio Industrial, evolución de su valoración, significado y rentabilidad en el contexto internacional”, Bienes Culturales. Revista del Instituto del Patrimonio Histórico Español (n. 7, 2007): 62

12 Ídem.

13 Ibídem, 63

14 En la página 11 del citado Plan Nacional se incluye el valor "territorial", que pudiera estar relacionado con este, aunque el término resulta ambiguo.

15 Linarejos Cruz e Ignacio Español, "Los paisajes de la industrialización”, Bienes Culturales. Revista del Instituto del Patrimonio Histórico Español (no. 7, 2007): 124.

16 Julián Sobrino, "El paisaje es energía", en I Congreso Internacional de Investigación sobre Paisaje Industrial. Sevilla 2, 3 y 4 de noviembre de 2011, Grupo de Investigación IPSJ.exel Laboratorio del Paisaje Industrial Andaluz (Andalucía: Consejería de Obras Públicas y Vivienda de la Junta de Andalucía 2011), 28. tatividad tipológica - dígase también de unicidad-, y los de autenticidad e integridad. Los dos últimos están muy asociados a la condición de los bienes patrimoniales como parte de un proceso evolutivo, en el cual todos tenemos responsabilidad.

Por su parte, Eusebi Casanelles incluye los valores de antigüedad, documento ${ }^{11}$ y carácter: este último también se conoce como valor de función. Sobre el primero comenta: "somos la primera generación que damos la categoría de bien patrimonial a objetos que nosotros mismos hemos utilizado y es justamente esta situación la que mentalmente impide que una parte de la población pueda considerar los bienes industriales como bienes patrimoniales culturales".12 Por esto las acciones de sensibilización y divulgación resultan extremadamente importantes en la gestión patrimonial.

Por otra parte, resulta significativo el acento que Casanelles pone sobre la relación de la industria con el paisaje, al considerar que este vínculo refuerza el valor de singularidad del primero -y de ambos si se observan como elementos indisociables-, ya que para este autor:

\footnotetext{
"Una de las características del patrimonio industrial mueble e inmueble es su falta de singularidad, no son únicos [sino] repetitivos. [...]

La singularidad de diferentes lugares productivos de un mismo sector productivo y su importancia universal no los da la técnica, sino su entorno natural y social. Muy a menudo, las máquinas son idénticas o similares en diferentes sitios, pero la historia y el testimonio que ellas contienen no". ${ }^{13}$
}

Por ello, siempre que resulte pertinente, se debe fomentar la valoración y gestión integral del patrimonio industrial desde la perspectiva del paisaje. Esto connotaría en algunas industrias otro valor: el ambiental o paisajístico, ${ }^{14}$ dado a partir de las relaciones que por su carácter y desarrollo histórico establece con el paisaje cultural del cual forma parte. Asimismo, el valor de signo, subraya el significado que estos bienes o sitios han ofrecido y ofrecen a la comunidad.

En cuanto a su valor ambiental, debe tenerse en cuenta que "la mirada que la industrialización proyectó sobre su paisaje fue una mirada productivista y selectiva que buscaba la eficiencia del aprovechamiento intensivo de los recursos naturales de la provisión de energía y de la capacidad de transporte masivo"; 15 lo cual no limita que el resultado final también conlleve una valoración estética, aunque no haya sido una cualidad originalmente planificada a escala del paisaje.

\section{La perspectiva paisajista en la valoración del patrimonio industrial}

Esta concreción acentúa un enfoque de análisis que valora su objeto de estudio desde la heterogeneidad del marco general de desarrollo, hasta la especificidad de los elementos que aborda. Reconoce el valor del entorno y las influencias que en los dos sentidos se establecen con lo construido, en este caso de carácter industrial; así también la relación de la industria con otras funciones y escalas sociales, económicas, políticas, culturales y hasta geográficas; el papel de la sociedad y los procesos culturales como legado y como marca, el valor del tiempo y de los cambios; y los elementos intangibles que ha generado: costumbres, saberes, instituciones, organizaciones, etc.

En efecto, el valor del patrimonio industrial resalta por el entorno en que se encuentra, el paisaje que representa, las relaciones que establece, y las memorias y significados contenidos. Incluso, la noción de paisaje industrial, como conjugación y síntesis de la evolución de los conceptos de patrimonio industrial y paisaje cultural, dado el caso, resulta beneficiosa y conveniente. Para Julián Sobrino, "el paisaje supone un valor de primer orden pues, sin el entorno que lo hizo posible, el sitio industrial carecería de interés relacional, contextual”. ${ }^{16}$ No podría valorarse desde las razones que le dieron vida, impulsaron su desarrollo y ocasionaron sus 
Figura 4. Vista del sur del paisaje industrial portuario de La Habana. Fotografía de Alejandro Leal del Ojo.

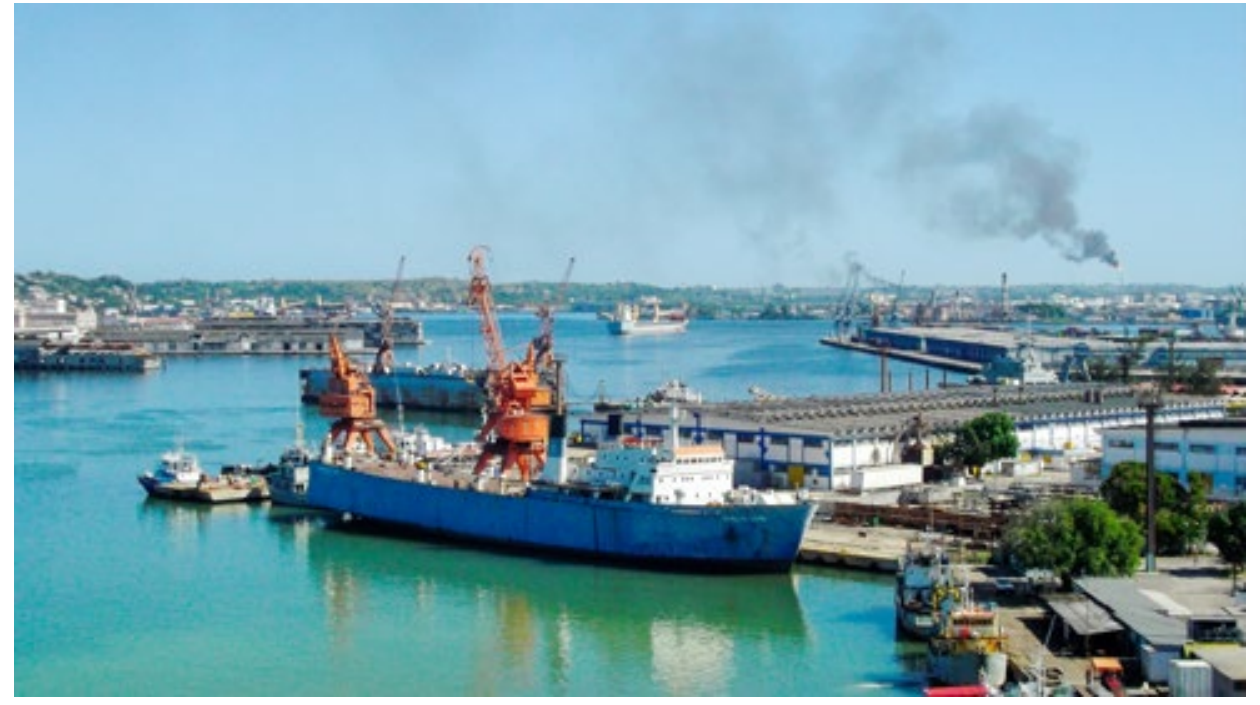

cambios; como tampoco se comprenderían las relaciones que ha establecido a diferentes escalas ni su huella. En definitiva, sin estudiar esta relación no podría valorarse el patrimonio industrial en toda su dimensión, y se perderían cualidades y capacidades imprescindibles para mantenerlo vivo y útil en el paisaje actual y para la sociedad contemporánea

El paisaje portuario vuelve a ser un ejemplo excepcionalmente rico por los elementos que involucra en su dinámica y naturaleza. Su ubicación en el litoral costero o la ribera fluvial le ofrece una fisionomía muy peculiar, que combina lo marítimo con lo terrestre, siendo siempre la presencia del agua un componente de gran influencia. El espacio de interrelación entre ambos, suele presentar una intensa actividad humana y estructuras muy concretas creadas durante la evolución de las funciones del puerto. Es un espacio de abrigo, aunque su explotación responde a intereses económicos que lo insertan en una logística de comunicación e intercambio muchas veces internacional, por lo que es considerado un espacio articulador por excelencia. Por ello influye de muy variadas formas en la población, en su carácter, creencias, conocimientos, comportamiento y relación con otros.

Tiene el puerto gran importancia territorial, económica, cultural y paisajística, y una fuerte relación con la industria. Es precisamente esta última la que ha ofrecido unidad al paisaje portuario, y continuidad a su análisis histórico asentado en los cambios tecnológicos. A pesar de los cambios de la relación puerto-ciudad ocurridos en el siglo XX, quedan huellas - con fortuna indelebles- en su entorno, así como en el centro histórico urbano aledaño. Son evidentes en el trazado de la ciudad, en la toponimia, en la arquitectura civil pública, doméstica y militar, en el notable patrimonio industrial, y en su gente. Por lo que se reconoce su influencia a nivel urbano, social, económico y cultural; así como la hegemonía, en apariencia evidente, de elementos dedicados al transporte, el comercio, la producción, la infraestructura técnica y la transformación de energía.

Entendido de esta forma el estudio del espacio portuario se enriquece notablemente. Al articular en él las variables del paisaje, se enlaza su dimensión medioambiental con el entorno natural, la dimensión urbana con lo construido, la dimensión económica con la sociedad y la dimensión cultural con la identidad. Todo tamizado por el valor del tiempo que ofrece la perspectiva de la sedimentación, a la vez que ilustra un proceso vivo, en constante evolución y reforma. Resulta esencial reconocer el valor del puerto en el desarrollo histórico de la ciudad, en su identidad e imagen actual, así como recurso para su proyección hacia el futuro, aun con las adecuaciones que necesita y estima la sociedad contemporánea. 
ZARCH No. 16 | 2021

Rehaciendo el patrimonio arquitectónico controvertido, repensando el espacio público

Remaking Contested Architectural Heritage, Rethinking Public Space

\section{YANELI LEAL DEL 0JO DE LA CRUZ}

El paisaje en la interpretación del patrimonio industrial. Los puertos

The landscape on industrial heritage interpretation. The ports

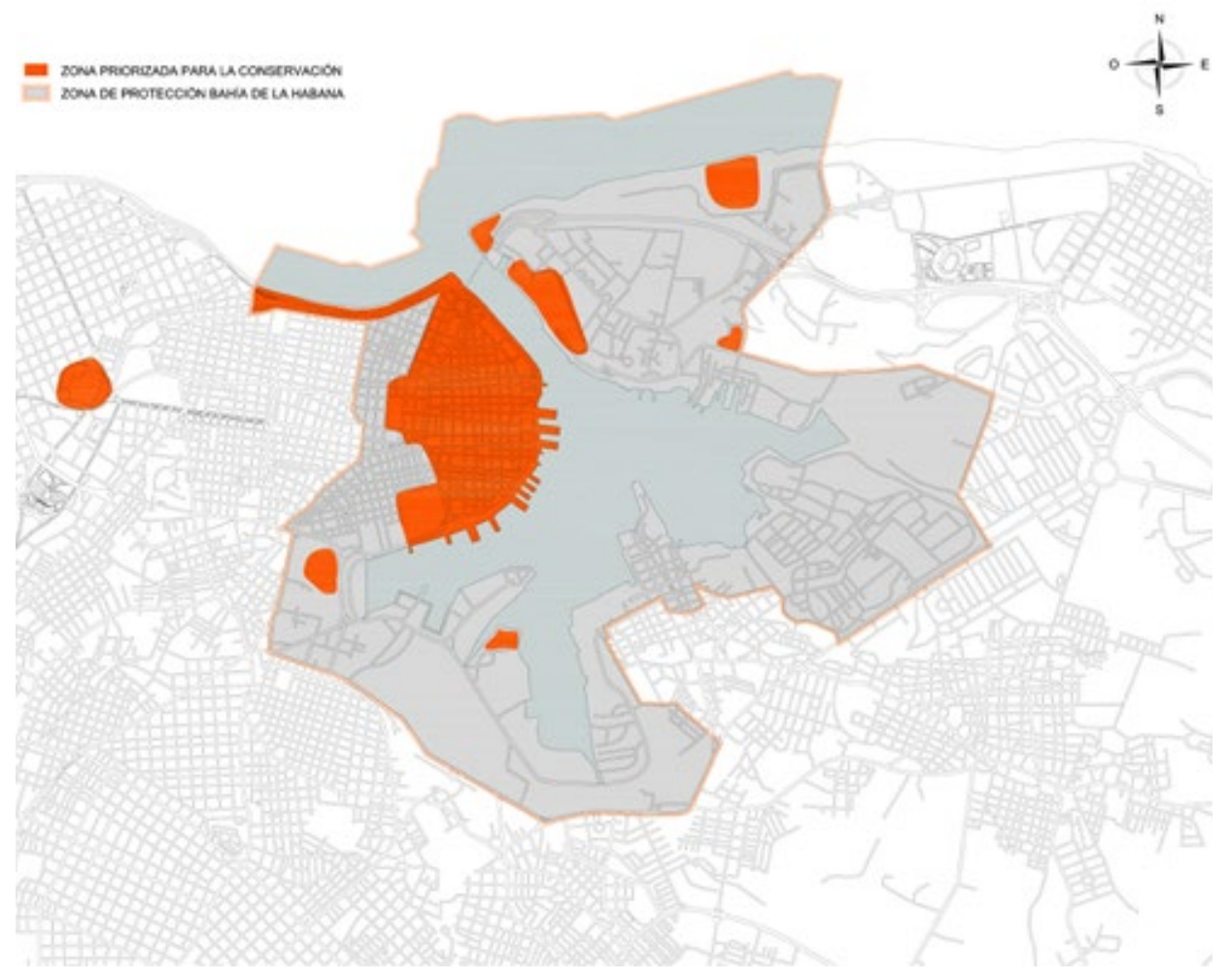

Figura 5. La bahía de La Habana y su zona de amortiguamiento. Plano realizado por Alejandro Leal del Ojo.

La rehabilitación de los puertos debe asumirse como un proyecto de grandes oportunidades para el redimensionamiento de la identidad marítima. La postura más adecuada sería precisamente la que propicie la convivencia - más que la integración- entre puerto y ciudad, es decir, el diseño de un planeamiento en común que ofrezca un adecuado equilibrio a cada una de las partes. ${ }^{17}$ Esto es posible si la perspectiva del paisaje modela el estudio e interpretación del sitio industrial, y también su rehabilitación y gestión patrimonial.

Recientemente, se ha diseñado un plan de manejo integral para el puerto de La Habana que constituirá el mayor proyecto de este tipo en el contexto latinoamericano. ${ }^{18}$ En su propuesta sintetiza lo antes planteado. El primer paso estuvo en reconocer la bahía como zona de amortiguamiento del centro histórico de La Habana Vieja (Patrimonio de la Humanidad, en 1982) y, como tal, declararla Zona de Protección de la República de Cuba, en 2014. (Figura 5)

Desde esta interdependencia, el proyecto implica la reanimación del puerto como zona cultural, reconociendo su evolución histórica y papel en la identidad habanera. En balance con el Plan de Desarrollo Integral que se implementa en el centro histórico desde 1998, la bahía cuenta hoy con un plan de manejo medioambiental para el rescate del ecosistema marino (1998); con la delimitación de zonas de riesgo arqueológico (2014), en las que se han identificado valiosos bienes industriales en el borde costero y sumergidos; y con un Plan de Manejo del Paisaje Cultural (2017), donde la industria constituye uno de sus elementos más destacables.

En torno al puerto se han catalogado 100 bienes pertenecientes a diversas ramas de la industria pero que se perciben entrelazados. Y con la identificación de veinte unidades del paisaje se posibilita un mejor ordenamiento territorial, desde el estudio individual de las zonas que conforman el puerto habanero. El plan intenta solucionar la rehabilitación del patrimonio edilicio fabril, la devaluada situación medioambiental, la accesibilidad y desconexión de la ciudad con el borde costero 
por la escasez de espacios públicos asociados al frente de agua y la interposición de la infraestructura industrial y portuaria, entre otros. Con ello se han dirigido nuevos objetivos de desarrollo hacia una zona que había quedado por varias décadas preterida y que se percibe en desconexión con la ciudad, aunque constituye parte significativa de su historia e identidad cultural.

\section{Concienciación y participación ciudadana ante el paisaje cultural}

El desconocimiento sobre el patrimonio industrial de La Habana, como sucede en otras ciudades portuarias, media en la vulnerabilidad de los inmuebles, la infraestructura tecnológica, los modos de organización y el conocimiento revelado de cada sistema de industrias, influyendo finalmente en la identidad urbana. Este conflicto oscila de manera transversal sobre la adecuada interpretación y gestión del paisaje cultural. De ahí el valor de un modelo de comunicación integrado al plan de manejo que persiga la sensibilización ciudadana e institucional para la preservación del patrimonio portuario y su puesta en valor. Un modelo que comparta el enfoque sistémico con que se interpreta el paisaje industrial y que pueda contribuir a su análisis crítico.

Hasta hace poco la gestión patrimonial correspondía completamente a las autoridades, dígase al gobierno y a las instituciones estatales creadas para ese fin. En ocasiones, también se han sumado algunas asociaciones civiles, principalmente de vocación filantrópica, que han contribuido con estudios, con la movilización de recursos y con gestiones de reclamo. Sin embargo, hoy se reconoce la importancia de articular para este propósito un mayor número de actores que incluyen, de manera general, a la ciudadanía y a las entidades que desde el punto de vista administrativo o jurídico están relacionadas con el bien patrimonial. Esto resulta fundamental para la gestión integral de los proyectos, y para el mantenimiento y uso adecuado de las obras y sitios patrimoniales antes y después de su rehabilitación.

Es imprescindible que no solo los especialistas tengan conciencia de lo que el patrimonio representa, de sus valores y necesidad de conservación. El derecho a hacer uso de él, obliga a todos a su cuidado y protección. Por eso los documentos normativos refieren la necesidad de lograr una sensibilización ciudadana mediante la información y divulgación de los valores patrimoniales del bien. La apropiación social del mismo fomentaría su conservación y disfrute, así como la postura de corresponsabilidad deseada.

Este es un proceso cuyos resultados se observan a largo plazo, por lo cual la respuesta de la ciudadanía está en correspondencia con la evolución de las teorías del patrimonio, pero con cierto desfase dependiendo de la idiosincrasia, valores y perspectivas de cada sociedad, de ahí la importancia de la formación cultural. Para aquellas áreas del patrimonio de reciente reconocimiento y evaluación, urge la divulgación de su significado, si se quiere evitar la pérdida o deterioro continuado por desconocimiento o ignorancia. Dicha sensibilización se concreta a partir de la educación convencional y no convencional de los individuos, para la cual debe hacerse uso de todos los medios disponibles, con creatividad y flexibilidad, adecuándose a las particularidades del lugar, de la sociedad y sus recursos.

\section{Conclusiones}

Una gestión eficiente del patrimonio industrial debe ser consecuente con todos los elementos que involucra, y debe entenderlo como un sistema en el que muchas veces se incluyen aspectos generadores de conflicto moral, estético, de planificación territorial y económica. A pesar del gran valor que tiene la bibliografía asociada al patrimonio industrial y a los paisajes culturales, no se ha arraigado una concien- 


\section{ZARCH No. 16 | 2021}

Rehaciendo el patrimonio arquitectónico controvertido, repensando el espacio público

Remaking Contested Architectural Heritage, Rethinking Public Space

\section{YANELI LEAL DEL OJO DE LA CRUZ}

El paisaje en la interpretación del patrimonio industrial. Los puertos

The landscape on industrial heritage interpretation. The ports cia de los vínculos que existen entre ambos, lo cual repercute directamente en la vulnerabilidad del primero y el mal manejo de ambos. El valioso punto de vista que ofrecen los estudios del paisaje, y la necesidad de una educación patrimonialista con esta misma mirada, pueden constituir una herramienta para alterar el carácter controversial de la industria como patrimonio.

Ya sea en la conservación de elementos aislados o de conjuntos industriales, paisajes, sistemas y redes, la valoración del patrimonio industrial representa un gran reto: desde la exaltación del elemento que pervive como testimonio de un complejo mayor y que aún transmite los valores del conjunto; al aceptar que el patrimonio industrial influye en la conformación de un paisaje determinado y que este último interfiere en la dinámica de su constitución y evolución; en la identificación de estructuras aisladas cuya valoración en serie las fortalece; o al establecer redes que repercuten en la ordenación territorial, movilidad de las personas, ideas y mercancías.

Gestionar el paisaje como recurso para el desarrollo sostenible implica involucrar a la sociedad que lo habita en la toma de decisiones, y compartir con ella la responsabilidad de su salvaguarda y uso. Es importante que pueda identificar los significados del paisaje y los elementos patrimoniales que contiene, y que reconozca su capacidad transformadora como actor clave de un proceso vivo y dinámico. Dentro del paisaje portuario, la industria representa uno de sus elementos de mayor entidad. Reconocer su interdependencia posibilita una mejor valoración de ambos y con ello una gestión equilibrada que garantice el desarrollo continuo, diverso, equitativo, responsable y ético del sitio patrimonial. En pos de la sostenibilidad y mejora de la calidad de vida, en palabras de Martínez de Pisón, "es deseable un incremento de la conciencia paisajística que lleve a una demanda social de derecho al paisaje; un aumento de la cultura paisajista que reclame una relación con paisajes cuidados, atendidos, conservados como un derecho". 19 Gestionar ciudad y puerto en equilibrio significa hacer uso de ese derecho.

\section{Bibliografía}

Aguiló, Miguel. 1999. El paisaje construido. Una aproximación a la idea de lugar. Madrid: Editorial Castalia, S.A.

Alemany, Joan. 2015. Incidencia del puerto en la ciudad. La experiencia latinoamericana de renovación de los waterfronts. Revista Transporte y Territorio, n. 12: 70-89.

Alemany, Joan; Bruttomesso, Rinio, ed. 2011. La Ciudad Portuaria del siglo XXI. Nuevos desafíos en la relación Puerto-Ciudad. Venecia: RETE.

Andrade, María José. 2014. Puertos: Paisajes de memoria, lugares de oportunidad. eDap: documentos de arquitectura y patrimonio, n. 7: 28-37.

Aníbarro, Miguel Ángel. 2013. El lugar ante el paisaje. Cuadernos de Proyectos Arquitectónicos. Departamento de Proyectos Arquitectónicos de la ETSAM / UPM, n.4: 73-9.

Aníbarro, Miguel Ángel. 2014. El paisaje como patrimonio en evolución. En Proyectar la memoria. Vol. 2 de Criterios y estrategias para la intervención, restauración y gestión del Patrimonio Cultural Iberoamericano, coords. Rafael Guridi, Joaquín Ibáñez y Fernando, 113-23. España: Editorial Rueda S.L.

Aníbarro, Miguel Ángel; Valdés, Esther. 2016. Fascinante y detestable. Artelización e integración de los paisajes industriales. Cuaderno de Notas. Publicación sobre temas de teoría e historia de la arquitectura (julio): 1-18.

Bergeron, Louis. 2003. Patrimoine des ports, patrimoine de l'industrie: de l'ambiguïté à l'analogie. Portus, n. 5: 18-23.

Casanelles, Eusebi. 2007. Nuevo concepto de Patrimonio Industrial, evolución de su valoración, significado y rentabilidad en el contexto internacional. Bienes Culturales. Revista del Instituto del Patrimonio Histórico Español, n. 7: 59-70.

Centro de Estudios Paisaje y Territorio. 2015. El Paisaje en la Ordenación y Gestión de los Puertos de Andalucía. Sevilla: Agencia Pública de Puertos de Andalucía y Consejería de Fomento y Vivienda de la Junta de Andalucía. y territorio", en La construcción social del paisaje, Joan Nogué ed. (Madrid: Editorial Biblioteca Nueva, S.L., 2007), 334 
Cruz, Linarejos; Español, Ignacio. 2007. Los paisajes de la industrialización. Bienes Culturales. Revista del Instituto del Patrimonio Histórico Español, no. 7: 119-31.

Desfor, Gene; Laidley, Jennefer. 2011. Changing urban waterfronts: a fixity and flow perspective. Portus, n. 21: 6-11.

Fuentes, Francisco J. 2011. La experiencia cualitativa en el paisaje y el patrimonio construido. Apuntes. Revista de estudios sobre patrimonio cultural (julio-diciembre): 166-77.

Garrido, Francisco. 2014. Topofilia, paisaje y sostenibilidad del territorio. Enrahonar. Quaderns de Filosofia, n. 53: 63-75.

Gomes, Zandor. 2016. O patrimônio industrial como elemento da paisagem cultural e a paisagem cultural conformando o patrimônio industrial: uma relação conceitual. Espaço e Cultura (julio-diciembre): 27-48.

Grupo de Investigación IPSJ.exel Laboratorio del Paisaje Industrial Andaluz. 2011. I Congreso Internacional de Investigación sobre Paisaje Industrial. Sevilla 2, 3 y 4 de noviembre de 2011. Andalucía: Consejería de Obras Públicas y Vivienda de la Junta de Andalucía.

Menéndez, Sonia coord. Plan de gestión del Patrimonio arqueológico para el Centro Histórico de La Habana. Documento inédito del Gabinete de Arqueología de la Oficina del Historiador de la Ciudad de La Habana: 30 páginas.

Nogué, Joan, ed. 2007. La construcción social del paisaje. Madrid: Editorial Biblioteca Nueva, S.L. Nogué, Joan, ed. 2008. El paisaje en la cultura contemporánea. Madrid: Editorial Biblioteca Nueva, S.L.

Pavía, Mónica; Martínez, Yoser. 2016. Exploraciones arqueológicas subacuáticas en el Litoral Habanero. Gabinete de arqueología, n. 12: 57-68.

Pérez, José J.; Arés, María Elena. 2017. What is the industrial and technical heritage? Understand it to preserve it. Building \& Management (mayo-agosto): 46-52.

Plan Maestro. 2017. Plan de Manejo Paisaje Cultural Bahía de La Habana. Avance. La Habana: Plan Maestro de la Oficina del Historiador de la Ciudad de La Habana.

Prelorenzo, Claude. 2009. Les Cultures du paysage portuaire. Divergences et convergences entre port et ville. Portus, n. 18: 50-5.

Rigol, Isabel; Rojas, Ángela. 2012. Conservación patrimonial: teoría y crítica. La Habana: Editorial $\mathrm{UH}$.

Sanz, Marina y Julián Sobrino. s.a. Patrimonio Industrial y Obra Pública como recurso didáctico. Los puertos. España: Consejería de Educación y Ciencia. Junta de Andalucía.

Uriarte, Iñaki. 2005. La industria, fábrica del paisaje. En I Congreso Internacional de Paleosiderurgia y Recuperación de Patrimonio Industrial. Hierro. Historia y Patrimonio, 443-53. España: Insmet-Tecnalia.

\section{Sitios web:}

Plan Nacional de Patrimonio Industrial. Actualización de 2016. http://www.culturaydeporte.gob. es/planes-nacionales/dam/jcr:eba404cd-e170-419d-b46a-e241ebd1b1b0/04-texto-2016-pnpiplan-y-anexos.pdf (consultada el 13 de junio de 2020)

Principios conjuntos de ICOMOS-TICCIH para la conservación de sitios, estructuras, áreas y paisajes de patrimonio industrial, «Los Principios De Dublín», 28.11.2011. http://www.consejocentrohistoricopuebla.com/wp-content/themes/Web_Consejo/doctos/internacional/2011_Principios_de_Dublin.pdf (consultada el 30 de abril de 2019)

TICCIH. Carta de Nizhny Tagil sobre el Patrimonio Industrial. Moscú, julio de 2003. https://www. icomos.org/18thapril/2006/nizhny-tagil-charter-sp.pdf (consultada el 13 de junio de 2020) 